\title{
La jerarquización de las cecas de Sekaisa y Bílbilis
}

\author{
Leandre Villaronga *
}

El problema de la jerarquización de las cecas de Sekaisa y Bílbilis a que han hecho referencia Burillo y Ostalé (Burillo, Ostalé 1983-84), al preguntarse como podian estar tan próximas ambas ciudades contradiciendo alguno de los enunciados metodológicos de la arqueología espacial, vamos a intentar explicarlo estableciendo una hipótesis de trabajo.

Aceptamos la situación geográfica para dichas ciudades propuesta por Burillo y Ostalé (Burillo 1986; Ostalé 1987).

Bílbilis, celtibérica, situada en Valdeherrera, en la margen izquierda del río Jiloca en su confluencia con el Jalón. Después la ciudad hispanolatina de Bílbilis-Itálica se sitúa en el Cerro de Bámbola. La distancia entre ambas es de unos $7,500 \mathrm{kms}$.

Sekaisa, su primer establecimiento en Poyo de Mara, ampliado después a poca distancia en Belmonte, ambos en el valle del río Perejil.

La distancia entre ambos asentamientos, que dieron origen a dos cecas importantes, es pequeña para dar cabida a dos ciudades, importantes centros emisores.

Nuestro método de estudio en este caso será esquematizar las emisiones de ambas cecas, para ver sus coincidencias o sus alternancias cronológicas. Para ello tomaremos en consideración las emisiones con numerosas monedas, dejando aquellas de las que se conocen pocos ejemplares, por ser por el momento de dificil ordenación.

\footnotetext{
* Societat Catalana d'Estudis Numismàtics (Institut d'Estudis Catalans)
} 
Para Sekaisa ${ }^{1}$, formamos cuatro principales grupos de emisiones:

1. Con símbolo leona delante, Vives ${ }^{2} 64-2$, peso medio de 12,39 g., de igual sistema metrológico que la emisión de Kese sin símbolo, de principios del siglo II a.C. (Villaronga 1979).

2. Con símbolo leona detrás. Vives $64-3$ a 8 , peso medio de 14,14 gramos, del sistema de 10 monedas en libra, del cual son mitades. De mediados del siglo $\|$ a.C.

3. Con símbolo ME, Vives $65-2$, de peso medio de $18,51 \mathrm{~g}$., del sistema de 12 monedas en libra en reducción. Corresponden a la segunda mitad del siglo ॥ a.C.

4. Con símbolo de delfín delante y otro detrás, Vives $65-6,7,11$ y 13, peso medio de $8,58 \mathrm{~g}$., similar a las últimas emisiones ibéricas de Kese. Del primer tercio del siglo I a.C.

Para obtener la ordenación y cronología de Bílbilis, partimos del grupo que establecimos para las monedas ibéricas de Tarraco de finales del siglo II a.C. (Villaronga 1979), las cuales presentan un aumento de peso y una intensa romanización en su leyenda, que atribuimos al paso de los Cimbrios en el año 104 a.C. Dichas emisiones son las siguientes:

Kese, símbolo NS, Vives 36-7, peso medio de 13,22 g., desviación típica de 1,08, e intervalo de confianza para la media de 12,39/14,05 g.

Kese, símbolo BE, Vives $36-4$, peso medio de $11,91 \mathrm{~g}$., desviación típica de 1,50, e intervalo de confianza de 11,47/12,35 g.

Kese, símbolo TE, Vives $36-1$, peso medio de $11,73 \mathrm{~g}$., desviación típica de 1,48 e intervalo de confianza de $11,09 / 12,37 \mathrm{~g}$.

De éstas, el intervalo de confianza de la primera encaja dentro del sistema metrológico semiuncial romano, y las otras dos con un peso ligeramente inferior quedan algo por debajo de aquel.

Podemos ver que las emisiones de Bílbilis encajan dentro del sistema metrológico de estas emisiones kesetanas.

- Para la ordenación de las emisiones de Sekaisa no tomamos en consideración las ordenaciones propuestas últimamente (Dominguez 1982; Ostalé 1987), pues estimamos que no presentan una discusión suficiente, y seguimos la propuesta por nosotros (Villaronga 1987; García Garrido y Villaronga 1987).

${ }^{2}$ La referencia a Vives, lo es siempre a su obra (Vives 1926). 
Bílbilis, con símbolo $\mathrm{S}$, Vives 63-1, 3 y 4, peso medio de 12,71 g., desviación típica de 2,01 e intervalo de confianza para la media de 12,39/ 13,02 .

Bílbilis, con símbolo $\mathrm{BI}$, Vives $63-5,7,8,9,10$ y 11 , peso medio de $11,85 \mathrm{~g}$., desviación típica de 2,07 e intervalo de confianza de 11,56/ 12,24 .

La primera encaja perfectamente con la emisión de Kese de símbolo NS, y la segunda con las emisiones de Kese con los símbolos BE y TE.

Para la comprobación estadística (Villaronga 1985) de estos grupos realizamos el análisis de varianzas, obteniendo para el primer grupo, formado por Kese con NS y Bílbilis con $S$, una $F=0,579$, con 1 y 168 grados de libertad, aceptable el 44 por 100 , siendo también aceptable el test de Barlett al 4,6 por 100. Presentando este grupo en conjunto una media de $12,73 \mathrm{~g}$., y un intervalo de confianza para la media de 12,44 / 13,02 .

Para el segundo grupo, formado por las emisiones de Kese con símbolo TE y $\mathrm{BE}$, y Bílbilis con $\mathrm{BI}$, obtenemos una $\mathrm{F}=0,069$, con 2 y 266 grados de libertad, aceptable al 93 por 100. Lo que permite asegurar que pertenecen a la misma población.

En cambio el test de Barlett está en el límite de aceptación del 1 por 100. Esto es debido a que la emisión de Bílbilis presenta una dispersión de pesos en torno a la media superior a las que presentan las emisiones de Kese, fruto de un trabajo técnico del taller de inferior calidad. La media de este grupo es de $11,85 \mathrm{~g}$. y el intervalo de confianza de $11,67 /$ 12,07 .

A este grupo coetáneo del paso de los Cimbrios podemos añadir otras emisiones ibéricas, que lo aumentan y lo confirman. Asi la emisión ibérica de Iltirta 34 (Villaronga 1978), la cual consideramos posterior a las 23,28 y 31 por razones epigráficas y estilísticas, presentaba un peso superior a aquellas, anomalia que en aquel momento no supimos explicar. Ahora vemos que se trata de una emisión en la cual el peso aumenta con relación a las anteriores como sucede en Kese.

También se presenta este aumento de peso en Sekia, en la emisión con dos delfines, Vives $42-9,10$ y 11 , y en la de Kelse del tipo de peinado en líneas, Vives 62-7.

Sus parámetros estadísticos son: 
Iltirta, emisión 34 (Villaronga 1978), peso medio de 11,62 g., desviación típica de 1.326 e intervalo de confianza para la media de 11,36/ 11,87 .

Sekia, con dos delfines, Vives $42-9,10$ y 11 , peso medio de 11,53 gramos, desviación típica de 3,48 e intervalo de confianza de 10,80/ 12,27 .

Kelse, Vives 62-7, peso medio de 11,32 g., desviación típica de 1,79 e intervalo de confianza de 10,83/11,81.

Del análisis de varianzas entre las emisiones de este segundo grupo, formado por Kese con símbolos TE y BE, Bílbilis con BI, Iltirta 34, Sekia y Kelse, para comprobar si pertenecen todas a la misma población, obtenemos una $F=0,746$, con 5 y 510 grados de libertad, aceptable al 58 por 100. El test de Barlett no es aceptable, por la gran dispersión de los pesos, especialmente en la muestra de Sekia.

El peso medio de este grupo es de $11,69 \mathrm{~g}$., y el intervalo de confianza para la media es de $11,50 / 11,88$.

Damos a continuación los gráficos de los intervalos de confianza.

Para el primer grupo tenemos un intervalo de confianza común de $12,39 / 13,02$.

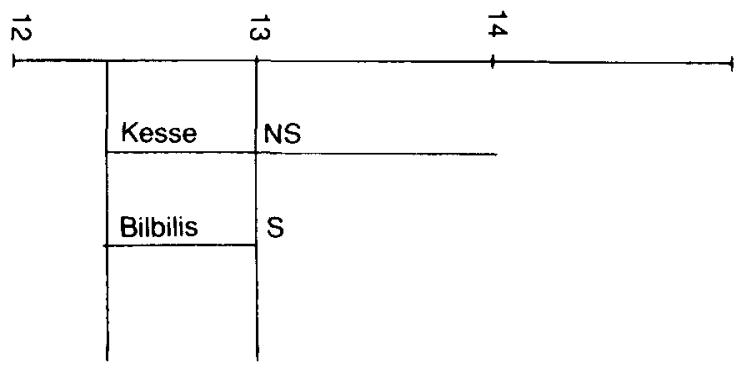

Para el segundo grupo, el intervalo de confianza común es de 11,56/ 11,87 . 


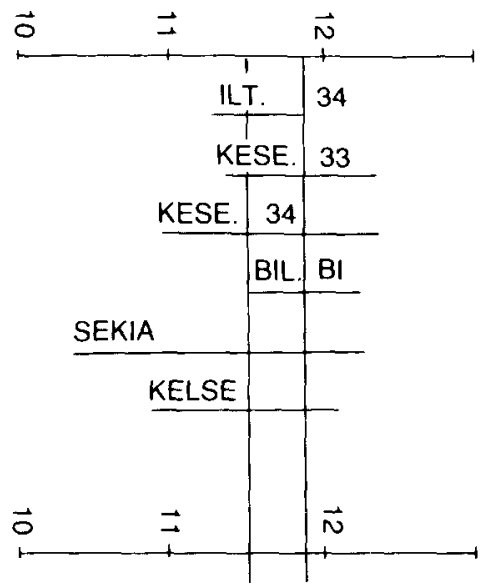

Resultando para las emisiones de Bílbilis la siguiente ordenación:

1. Emisiones con leyenda ibérica con los símbolos $\mathrm{S}$ y $\mathrm{BI}$, de fines del siglo "I a.C., coetáneas con el paso de los Cimbrios.

2. Emisión con la leyenda latina Bíbilis Itálica, con la efigie de Augusto, sin titulatura imperial, Vives 138-1 a 5, algo anterior al año 27 a.C.

3. Emisión con leyenda latina Bílbilis, cabeza de Augusto y titulatura imperial, con reverso de jinete y sin magistrados, Vives 138-6 a 10, de después del 27 a.C.

4. Siguen las emisiones de Augusto, con reverso de laurea y nombre de magistrados, Vives 139-1 a 5 .

5. Emisiones de Tiberio, Vives $139-6$ a 8.

6. Emisión de Caligula, Vives 139-9.

Si hacemos una ordenación de conjunto, vemos que no hay coincidencias cronológicas, existiendo en cambio unas alternancias, pues cuando se acuña en Sekaisa no se acuña en Bílbilis y a la inversa sucede lo mismo.

Podemos establecer una ordenación de conjunto:

1. Principios del siglo II a.C., acuña Sekaisa, con leona delante.

2. Mediados del siglo II a.C., continúa Sekaisa, con las emisiones de leona detrás.

3. Segunda mitad del siglo ॥ a.C., continúa Sekaisa con la emisión con símbolo SE. 
4. Fin de siglo II a.C., acuña Bílbilis con leyenda ibérica y símbolos $S$ y $\mathrm{BI}$, estando la ciudad asentada en Valdeherrera.

5. Primer tercio del siglo I a.C., vuelve a acuñar Sekaisa la emisión con dos delfines.

6. Poco antes del 27 a.C. acuña Bílbilis asentada en el cerro de Bámbola con la leyenda Bílbilis Itálica

7. Después del 27 a.C. acuña Bílbilis con cabeza de Augusto y sin titulatura imperial.

8. Del 27 a.C. a 14 d.C., acuña Bílbilis con efigie de Augusto y titulatura imperial. berio.

9. Del 14 al 37 d.C., acuña Bílbilis las emisiones a nombre de Ti-

10. Del 37 al 41 d.C., acuña Bílbilis las emisiones de Calígula.

\section{CONCLUSIONES}

1. Durante el siglo II a.C. es Sekaisa quien acuña moneda, su jerarquía es evidente.

2. A fin del siglo ll a.C. deja de acuñar Sekaisa y entra en acción la ceca de Bílbilis, situada en Valdeherrera. El cambio de jerarquización lo atribuimos a un cambio de sentido político, producido por un aumento de la romanización, que deducimos por lo acaecido en Tarraco y atribuimos al paso de los Cimbrios, el año 104 a.C.

3. Pasa el peligro y al igual de lo sucedido en Tarraco todo vuelve a quedar igual a como estaba antes, y es Sekaisa quien vuelve a acuñar. Bílbilis deja de acuñar y quizás es en este momento o poco después, en que la ciudad situada en Valdeherrera decae, camino de su desaparición.

4. En época augústea vuelve a acuñar Bílbilis, esta vez ya situada en el Cerro de Bámbola, la romanización avanza y continuará acuñando hasta tiempos de Calígula.

5. Se presenta una verdadera alternancia entre las dos ciudades, pasando la jerarquía de una a la otra según las circunstancias políticas. Cuando predomina lo íbero se acuña en Sekaisa, cuando es la romanización la que predomina se acuña en Bílbilis. 
6. Esta jerarquización alternativa permite explicar la existencia tan próxima de dos cecas importantes, por sus múltiples y abundantes emisiones monetarias. 


\section{BIBLIOGRAFÍA}

Burillo, F., Ostalé, M., 1983-1984: Sobre la situación de las ciudades celtibéricas Bilbilis y Segeda. Kalathos, 3-4, págs. 287-309.

Burillo, F., 1986: Aproximación diacrónica a las ciudades antiguas del valle del Ebro, Teruel.

Domínguez, A., 1982: Ensayo de ordenación del monetario de la ceca de Sekaisa, La Moneda Aragonesa, Zaragoza.

García Garrido, M., Villaronga, L., 1987: Las monedas de la Celtiberia, Gaceta Numismática, 86-87, págs. 38 y 55 .

Ostalé, M., 1987: Numismática de la Celtiberia, Gaceta Numismática, 8687, págs. 121-137.

VILLARONGA, L., 1978: Las monedas ibéricas de llerda, Barcelona.

-, 1979: Les monedes ibèriques de Tàrraco, Barcelona.

-, 1985: Estadística aplicada a la Numismática, Barcelona.

—, 1987: Numismática Antigua de Hispania, Barcelona. 